\title{
The perspectives and experiences of physiotherapists and general practitioners in the use of the STarT Back Tool Tool: A review and meta- synthesis
}

Julia Hill ( $\nabla$ julia.hill@aut.ac.nz )

Auckland University of Technology

Freya Try

Auckland University of Technology

Georgia Agnew

Auckland University of Technology

Nicola Saywell

Auckland University of Technology

Research Article

Keywords: STarT Back Tool, stratification, screening, qualitative, perspectives, chronic, back pain, physiotherapist, general practitioners

Posted Date: April 22nd, 2021

DOl: https://doi.org/10.21203/rs.3.rs-413054/v1

License: (c) (i) This work is licensed under a Creative Commons Attribution 4.0 International License. Read Full License 


\section{Abstract}

Background: Chronic low back pain is associated with disability and work absence. Stratified primary care management of acute low back pain using a prognostic screening tool (STarT Back Tool, SBT) triages people with LBP into targeted treatment groups, matched to their level of risk of chronicity. The SBT was designed for use in the health service in the United Kingdom (UK) where it has been shown to improve clinical outcomes, patient satisfaction, and reduce treatment costs and time off work. Successful implementation of the SBT in health care outside the UK is dependent on the health practitioners who will use it and the healthcare system in which they work. Gaining health practitioners' perspectives on the SBT is an important step in effective implementation.

Methods: A computerised search of qualitative literature was conducted across seven databases in March 2021 using keywords to identify studies that investigate the perspectives of physiotherapists and general practitionners on the use of the SBT in primary health care. Study quality was assessed using the CASP tool. Data were coded and analysed using reflexive thematic analysis.

Results: Eight articles met the inclusion criteria and included the views of general practitioners and physiotherapists from primary health care settings from four countries. Three overarching themes were created from the data, the first 'making it work', identifies factors that may influence implementation and continued use of the SBT in clinical practice. The second 'will I do it?', captured potential consequences of adopting the SBT and the third 'it's all about the patient' emphasised how the SBT may affect patients and their potential reactions to risk stratification and matched treatments.

Conclusions: Physiotherapists and general practitioners found using the SBT frequently enhanced their practice. General practitioners did express concerns about time constraints and the potential for the SBT to undermine their clinical experience. Findings from this study will inform modifications to contextualise the tool to each healthcare environment.

\section{Background}

Low back pain (LBP) is a significant problem worldwide; prevention and management strategies have not reduced escalating prevalence rates (1-8). A high proportion of those with LBP experience recurrent episodes over their lifetime $(9-13)$. It is estimated that approximately $10 \%$ of people with acute LBP go on to develop chronic LBP which often results in disability and work absence $(4,11,14,15)$. The impact on society is significant, in the personal cost of pain and suffering and the financial cost of treatment and work absence. $(6,16-18)$

Traditionally a biomedical approach has been used to manage LBP (23). However there is evidence of an association between psychosocial factors and the propensity for acute LBP to become chronic $(15,18,24-26)$. This has led to the development of management strategies which consider psychosocial factors. Several screening tools have been developed for the management of LBP; the STarT Back Tool Screening Tool (SBT) (28)

(http://www.keele.ac.uk/sbst/startbacktool/) was designed, developed and tested in the United Kingdom to support primary health care practitioners such as physiotherapists (PTs) and general practitioners (GPs). The evidence-based recommendation is for the SBT to be used at the first contact for each new LBP episode (National Institute for Health and Care Excellence [NICE], 2016). The SBT is a 9-item questionnaire prognostic screening tool which identifies modifiable psychosocial risk factors for developing chronic LBP (29). Patients are stratified to receive targeted treatment, matched to their level of risk (30): Low risk patients require one treatment session which includes assessment and evidence based education on self-management; medium risk patients also receive education on self-management and an additional six sessions of evidence based physiotherapy; high risk patients receive the same as for medium risk and psychologically informed physiotherapy $(15,31-33)$. This strategy of screening and matched care, supports health 
practitioners in clinical decision-making $(27,34,35)$. Stratification of people with LBP using the SBT has been shown to reduce health care costs, individual suffering and productivity loss in the UK $(4,15,33,36)$.

The SBT was initially validated for use in the National Health Service in the UK (31) and has since been used in a number of countries. However, the introduction of a stratification tool into a primary care setting is dependent on those who will administer it and the constraints imposed on them by the health care system in which they work (32). Understanding practitioners' perspectives will help address barriers to successful implementation of the SBT $(32,37)$. This study is a systematic review of studies investigating the perspectives of physiotherapists and GPs on the use of the SBT in clinical practice.

\section{Methods}

The review was conducted using Preferred Reporting Items for Review and Meta-Analysis guidelines (PRISMA; (38).

\section{Databases searched and inclusion and exclusion criteria}

The databases searched were CINAHL, MEDLINE, Sport Discus, EBSCO, Scopus, Web of Science, Cochrane Review Database, and Cochrane Central Register of Controlled Trials published in English in peer reviewed journals from the inception of the SBT (2008) to March 2021. Articles were included if they were of qualitative design or included qualitative data reported separately from quantitative data. Participants in the study were health practitioners (general practitioners or physiotherapists) working in primary care. We included studies which had collected data during face to face interviews, focus groups, telephone interviews or workshops. The focus was perspectives of previous use or intended future use of the SBT. All retrieved articles were imported into bibliographic management software (Endnote X8). Duplicates were identified and removed.

\section{Search strategy}

Search terms were developed to identify studies relating to the perspectives on the use of the SBT and were adapted for different databases (see Table 1). Four key term clusters were used, which identified the group of participants of interest; health care practitioners (physiotherapists and general practitioners), the intervention; stratified care (SBT), the condition of interest; low back pain, and the phenomenon of interest; and perspectives of those administering the tool.

\section{Appraisal of included papers}

Title and abstracts of articles were reviewed against inclusion criteria to identify relevant articles by two reviewers (FT and $\mathrm{JH}$ ). Full texts of articles where the title and abstract fit the inclusion criteria were reviewed using the same eligibility criteria by FT. JH independently reviewed the identified eligible articles. Where disagreement existed, NS acted as arbitrator. Reference lists of all included articles were searched for additional relevant articles and two authors, who have published widely in the area (Hill, JC and Caeiro, C) were contacted and invited to view the final article list to ensure all relevant literature had been included. 


\begin{tabular}{|c|c|}
\hline Criteria & Search terms used \\
\hline $\begin{array}{l}\text { Health care } \\
\text { practitioners: }\end{array}$ & \multirow{3}{*}{$\begin{array}{l}\text { "health* practitioner*" OR "health care pract*" OR "health* professional*" OR "health person*" } \\
\text { OR physiotherap* OR "physical therap*" OR "primary care*" OR "general pract*" OR gp OR doctor* } \\
\text { OR physician* OR nurse* OR pt }\end{array}$} \\
\hline Physiotherapist & \\
\hline $\begin{array}{l}\text { General } \\
\text { practitioners } \\
(\mathrm{GP})\end{array}$ & \\
\hline \multicolumn{2}{|l|}{ AND } \\
\hline \multirow[t]{2}{*}{ Stratified Care } & Stratified OR stratification OR stratifying OR (target* treatment*) \\
\hline & start-back" OR "STarT Back Tool \\
\hline \multicolumn{2}{|l|}{ AND } \\
\hline $\begin{array}{l}\text { Low back pain } \\
\text { (LBP) }\end{array}$ & $\begin{array}{l}\text { "low* back" OR "lumbar spine" OR "lumbar pain" OR Ibp OR "non specific back pain" OR "non- } \\
\text { specific back pain" }\end{array}$ \\
\hline \multicolumn{2}{|l|}{ AND } \\
\hline $\begin{array}{l}\text { Perspectives } \\
\text { (beliefs and } \\
\text { experiences) }\end{array}$ & $\begin{array}{l}\text { opinion* OR thought* OR perspective* OR experience* OR impression* OR view* OR training OR } \\
\text { support* OR administer* OR implement* OR attitude* }\end{array}$ \\
\hline
\end{tabular}

\section{Quality Assessment}

The Critical Appraisals Skills Programme (CASP; Critical Appraisal Skills Programme, 2018) tool was applied independently by two reviewers (F.T. and G.A.) to assess the quality of included articles. No article was excluded on methodological quality however the Cochrane Collaboration recommend this tool to assess confidence in the quality of a review (40). Any discrepancies of opinion were resolved using an additional reviewer (JH) to make the final decision.

\section{Data Extraction}

The following data were extracted from the included articles: study design, participants, country, and method of data collection. Two reviewers (F.T and G.A) extracted data independently from the results section of each paper in the form of direct quotes and summaries of participant interviews.

\section{Data Analysis}

Reflexive thematic analysis with an experiential orientation was used to gather findings and generate themes (41). This method captured the experience of the participants by focussing on the language used (42). Two reviewers (F.T. and G.A.) familiarised themselves with the data by reviewing and repeatedly reading the selected papers. Each article was coded line-by-line and the codes were grouped and categorised into candidate themes, (sub-themes) ensuring that the context of the original article was considered. The data were then reviewed by four reviewers (F.T., G.A., J. H. \& N.S.) and the candidate themes were grouped under overarching themes which went beyond the content of the original studies. Themes were finalised following multiple reviews of candidate themes and subsequently defined and named. Representative quotes were selected to support the themes. The aim of this was to develop themes which are more directly relevant to clinical practice.

\section{Results}




\section{Literature Search}

The process for study selection can be found in Fig. 1.

Six hundred and three journal articles were identified, 300 remained after removal of duplicates. Results from eight studies undertaken between 2011 and 2020 were included in the final review and meta-synthesis. Authors were contacted to request full publications of two abstracts that appeared relevant to this review; one was not published (43) and one author contacted twice did not reply (44). In the eight articles retrieved, 76 physiotherapists and 65 GPs were interviewed or surveyed about their perspectives on the use of the SBT.

Study Characteristics

A summary of the articles included in this review can be found in Table 2. Studies were completed in four countries: four in the UK, two in Germany and one each in the USA and Portugal between 2011 and 2020. Four studies interviewed participants following exposure and use for several months $(36,45-47)$. The remaining four studies reported on interviewed participants who had completed workshops where potential for the use of the SBT use was being investigated $(4,44,48,49)$.

Quality of Articles

All studies met at least seven of the ten criteria in the CASP tool, with the relationship between the researcher and included participants most frequently not addressed. (see Table 3 ).

Table 2

Summary of characteristics of included articles $(n=8)$

\begin{tabular}{|c|c|c|c|c|c|c|c|}
\hline Author & Year & Country & Design & Data Source & $\begin{array}{l}\text { Currently } \\
\text { using STarT } \\
\text { Back Tool }\end{array}$ & Profession & $\begin{array}{l}\text { Participants } \\
\text { (n) }\end{array}$ \\
\hline Hsu et al. & 2019 & USA & $\begin{array}{l}\text { Qualitative / } \\
\text { Observational }\end{array}$ & Interview & $\mathrm{Y}$ & PT & 7 \\
\hline $\begin{array}{l}\text { Karstens } \\
\text { et al. }\end{array}$ & 2015 & Germany & Qualitative & $\begin{array}{l}\text { Think tank } \\
\text { workshop }\end{array}$ & $\mathrm{N}$ & GP & 19 \\
\hline $\begin{array}{l}\text { Karstens } \\
\text { et al. }\end{array}$ & 2018 & Germany & Qualitative & $\begin{array}{l}\text { Think tank } \\
\text { workshop }\end{array}$ & $\mathrm{N}$ & PT & 19 \\
\hline $\begin{array}{l}\text { Sanders } \\
\text { et al. }\end{array}$ & 2011 & UK & $\begin{array}{l}\text { Qualitative / } \\
\text { Observational }\end{array}$ & Interview & Y & GP & 9 \\
\hline \multirow[t]{2}{*}{$\begin{array}{l}\text { Caeiro et } \\
\text { al. }\end{array}$} & \multirow[t]{2}{*}{2019} & \multirow[t]{2}{*}{ Portugal } & \multirow[t]{2}{*}{ Qualitative } & \multirow[t]{2}{*}{ Focus group } & \multirow[t]{2}{*}{$\mathrm{N}$} & \multirow[t]{2}{*}{$\begin{array}{l}\text { GPs and } \\
\text { PTs }\end{array}$} & \\
\hline & & & & & & & PT: 6 \\
\hline $\begin{array}{l}\text { Bamford } \\
\text { et al. }\end{array}$ & 2017 & UK & $\begin{array}{l}\text { Qualitative / } \\
\text { Observational }\end{array}$ & $\begin{array}{l}\text { Audit data } \\
\text { extraction }\end{array}$ & $\mathrm{Y}$ & PT & 18 \\
\hline $\begin{array}{l}\text { Sanders } \\
\text { et al. }\end{array}$ & 2014 & UK & Qualitative & $\begin{array}{l}\text { Interviews; face } \\
\text { to face and } \\
\text { telephone }\end{array}$ & Y & PT & 26 \\
\hline $\begin{array}{l}\text { Saunders } \\
\text { et al. }\end{array}$ & 2016 & UK & Qualitative & $\begin{array}{l}\text { Focus groups } \\
\text { and telephone } \\
\text { interviews }\end{array}$ & $\mathrm{N}$ & GP & 23 \\
\hline
\end{tabular}


Table 3

Quality assessment (CASP tool) results

\begin{tabular}{|c|c|c|c|c|c|c|c|c|}
\hline Study & $\begin{array}{l}\text { Bamford } \\
\text { et al., } \\
2017\end{array}$ & $\begin{array}{l}\text { Caeiro et } \\
\text { al., } 2019\end{array}$ & $\begin{array}{l}\text { Hsu } \\
\text { et } \\
\text { al., } \\
2019\end{array}$ & $\begin{array}{l}\text { Karstens } \\
\text { et al., } \\
2015\end{array}$ & $\begin{array}{l}\text { Karstens } \\
\text { et al., } \\
2018\end{array}$ & $\begin{array}{l}\text { Sanders } \\
\text { et al., } \\
2011\end{array}$ & $\begin{array}{l}\text { Sanders } \\
\text { et al., } \\
2014\end{array}$ & $\begin{array}{l}\text { Saunders } \\
\text { et al., } \\
2016\end{array}$ \\
\hline $\begin{array}{l}\text { Clear statement } \\
\text { of aims }\end{array}$ & $\mathrm{Y}$ & $\mathrm{Y}$ & Y & $\mathrm{Y}$ & Y & $\mathrm{Y}$ & $\mathrm{Y}$ & $\mathrm{Y}$ \\
\hline $\begin{array}{l}\text { Appropriate } \\
\text { methodology }\end{array}$ & $\mathrm{Y}$ & Y & Y & $\mathrm{Y}$ & Y & $\mathrm{Y}$ & $\mathrm{Y}$ & $\mathrm{Y}$ \\
\hline $\begin{array}{l}\text { Appropriate research } \\
\text { design }\end{array}$ & Y & $\mathrm{Y}$ & $\mathrm{Y}$ & $\mathrm{Y}$ & Y & $\mathrm{Y}$ & Y & $\mathrm{Y}$ \\
\hline $\begin{array}{l}\text { Appropriate } \\
\text { recruitment strategy }\end{array}$ & $\mathrm{Y}$ & $\mathrm{Y}$ & $\mathrm{N}$ & $\mathrm{N}$ & Y & $\mathrm{Y}$ & $\mathrm{Y}$ & $\mathrm{Y}$ \\
\hline $\begin{array}{l}\text { Data } \\
\text { collected appropriately } \\
\text { to address research } \\
\text { issue }\end{array}$ & $Y$ & $\mathrm{Y}$ & $\mathrm{Y}$ & $\mathrm{Y}$ & Y & $\mathrm{Y}$ & $\mathrm{Y}$ & $\mathrm{Y}$ \\
\hline $\begin{array}{l}\text { Relationship between } \\
\text { research } \\
\text { and participants } \\
\text { considered }\end{array}$ & $\mathrm{N}$ & $\mathrm{N}$ & $\mathrm{N}$ & $\mathrm{N}$ & $\mathrm{N}$ & $\mathrm{Y}$ & $\mathrm{N}$ & $\mathrm{Y}$ \\
\hline Ethical consideration & $\mathrm{Y}$ & $\mathrm{Y}$ & $\mathrm{Y}$ & $\mathrm{Y}$ & $\mathrm{Y}$ & $\mathrm{Y}$ & $\mathrm{Y}$ & $\mathrm{Y}$ \\
\hline $\begin{array}{l}\text { Rigorous data } \\
\text { analysis }\end{array}$ & $\mathrm{Y}$ & $\mathrm{Y}$ & $\mathrm{Y}$ & $\mathrm{N}$ & $\mathrm{Y}$ & $\mathrm{Y}$ & $\mathrm{Y}$ & $\mathrm{Y}$ \\
\hline $\begin{array}{l}\text { Clear statement } \\
\text { findings }\end{array}$ & $\mathrm{Y}$ & $\mathrm{Y}$ & $\mathrm{Y}$ & $\mathrm{Y}$ & Y & $\mathrm{Y}$ & $\mathrm{Y}$ & $\mathrm{Y}$ \\
\hline Value of research & $\mathrm{Y}$ & $\mathrm{Y}$ & $\mathrm{Y}$ & $\mathrm{Y}$ & $\mathrm{Y}$ & $\mathrm{Y}$ & $\mathrm{Y}$ & $\mathrm{Y}$ \\
\hline TOTAL (yes/10) & 9 & 9 & 8 & 7 & 9 & 10 & 9 & 10 \\
\hline
\end{tabular}

\section{Principle findings}

Three overarching themes were generated from the data:

1. Making it work, 2. Will I do it? and, 3. It's all about the patient.

Theme 1: Making it work

This theme identifies factors that may influence implementation and continued use of the SBT in clinical practice. It has four subthemes: help me, changing my practice, interprofessional relationships and system policies.

Help me refers to the support and skills participants felt they required to implement the SBT. Physiotherapists voiced their need for support, specifically supervision $(4,45)$.

But it's definitely true that it's something that not everybody can do [skilled communication] and it's hard to learn it on a theoretical basis. I think you'll need supervision on top. (Physiotherapist; Karstens et al., 2018) 
Additionally, physiotherapists identified specific areas of education they needed to manage psychosocial factors. They reported feeling under prepared by their tertiary education to undertake cognitive behavioural therapy, exercise prescription and the level of skilled communication required $(4,44)$.

I need to learn more about patient education, mainly how to use strategies from the cognitive-behavioural model in order to carry out education about the neurophysiology of pain. (Physiotherapist; Caeiro et al., 2019)

Changing my practice relates to how the SBT affected the way participants practised. Both professions felt it improved quality of care and reinforced or, in some instances, introduced evidence-based practice $(4,44)$.

[...] so, this may help moving physiotherapists from practices that are not evidence-based towards new and more effective treatments. (Physiotherapist; Caeiro et al., 2019)

Participants agreed that the SBT would help provide guidance for clinical reasoning and stratification of patients $(4,45$, $46,48,49)$.

I'd be happy with it saying, 'This is the most appropriate treatment,' because that's where you want to go. And more often than not you'll think, 'Yeah, that's more or less what I had in mind anyway.'... Or you'll go, 'Oh, that's a good idea. That wasn't quite what I was going to do but it might make sense'[...] (GP; Saunders et al., 2016)

Both professions also agreed it facilitated difficult conversations regarding psychosocial factors $(36,45,46,49)$.

Overall, the most helpful thing is it's really kind of given a framework to approach patients with... low back pain. Whereas in the past it's... not an easy clinic visit to lead [...] but now we have a bit of a framework to work in [...] (GP; Hsu et al., 2019)

Interprofessional relationships illustrates the relationships between GPs and physiotherapists in the implementation of the SBT. Three research groups identified that GPs were largely unaware of the physiotherapists' role in the use of the SBT (46-48).

Well, that would be desirable, if you knew what the physiotherapist really does in this case. (GP; Karstens et al., 2015)

Some physiotherapists hoped that the SBT would increase the trust GPs had in physiotherapists' ability to manage patients with LBP (4).

[...] our everyday reality is that there is little confidence in our capabilities [...] this approach enhances our own confidence as well as the physicians' trust in us, that the patients receive appropriate physiotherapy treatment. (Physiotherapist; Karstens et al., 2018)

Through STarT Back Tool training, GPs became more aware of physiotherapists' role in LBP treatment. This appeared to have a positive effect on interprofessional management, and to improve consistency between professions $(4,44-46)$.

[...] the GP is the first person the patient sees, if they could be better educated with regards to back pain and then that filtered down and everyone trying to do a fairly similar thing, not similar for every single problem but approaching problems in similar ways. (Physiotherapist; Sanders et al., 2014)

System policies refers to how specific health system policies affected the motivation of participants to use the SBT appropriately. GPs reported a fear of being penalised by insurance companies for overloading services, reduced their motivation to refer patients to physiotherapists $(47,48)$. 
[...] I wasn't going to get my wrists slapped, because you do sometimes get your wrists slapped [...] we get messages saying what the wait is for physio and you know, please don't overload us and we're often being told that so I try and manage. (GP; Sanders et al., 2011)

Physiotherapists also expressed concerns about restrictions placed on them from insurance companies. These included lack of freedom in decision making, prespecified time for consultations, and a restriction in the number of follow-up appointments. These restrictions could limit the appropriate use of the SBT (4). Physiotherapists reported that closer working relationships with GPs reduced waiting times (44) and the change in frequency and duration of consultations resulted in a reduced case load (46).

We may be seeing them over a longer period of time, but we're not seeing them as often. So that's working better for us from a case load point-of-view. (Physiotherapist; Sanders et al., 2014)

Theme 2: Will I do it?

This captured participants' conflicting perceptions of whether it was worth undertaking, and potential consequences of adopting it. There were five subthemes: 'is there time?', 'ability to change', 'recognise me', 'I know better', and 'changing me as a health professional'.

Is there time? examines whether there was time available in participants' sessions to administer the SBT I. Most GPs indicated that they lacked time to administer the SBT assessment and treatment recommendations $(44,47-49)$, with some GPs having as few as nine minutes per consultation (48). Some physiotherapists agreed that the SBT was time consuming for GPs and both professions suggested ways to reduce the time taken. For example, education being delivered remotely via media instead of face-to-face $(4,45,46,48)$.

[...] the problem is the time. It's definitely playing a major [part] on the issues you know. You're doing something a bit extra on top of what you normally do on a daily basis [...] (GP; Sanders et al., 2011)

In contrast, most physiotherapists found the tool quick and easy to use as it helped to speed up their clinical decision making $(4,44)$.

This tool is feasible in our context, because it includes only nine questions, which are easy to answer [...]. The outcome helps us on stratifying the patient and identifying treatment priorities. (Physiotherapist; Caeiro et al., 2019)

Ability to change, considers the factors affecting GP's and physiotherapist's ability to make the change required to implement the SBT. A factor that was pertinent to the success of SBT implementation was ensuring the local availability of recommended referral services (49).

Whatever decision you come out with, the care option that it's recommending must be embedded within the healthcare system that you're working in. So there's no point of having these treatment options in a tool if it's not going to be available in your practice area. (Physiotherapist; Saunders et al., 2016)

Another influencing factor was the reported stress associated with a change to routine care practises. Some participants forgot to use the tool in consults $(44,45,47)$.

My major difficulty was remembering to ask the questions because my practice is to enter my notes after the patient has left [...] and you think oh I've forgot to ask them. (GP; Sanders et al., 2011)

Recognise me refers to the factors that affected physiotherapists' motivation to upskill and treat more challenging patients. Due to the significant role they would play in the management of LBP patients using the SBT, physiotherapists 
advocated for increased recognition from health industry colleagues $(4,46)$.

[...] that would indeed be a first flagship. Meaning, that in medicine or even politics they would say: "look how important physiotherapy is!' (Physiotherapist; Karstens et al., 2018)

The reduction in the number of treatment sessions required for low-risk patients, with the consequent reduction in income was of concern to physiotherapists (4). This concern, combined with an increase in complexity of treatment required for high-risk patients, meant physiotherapists expressed a desire for remuneration to reflect the change (4).

I think reimbursement is rather cause of frustration for all of us therapists [laughter], we are convinced that we don't get paid to an extent we think we are qualified [...]. With these tasks [described for the STarT-Approach], with these additional qualifications, physiotherapy is gaining more, dramatically more importance and thus deserves a higher reimbursement. (Physiotherapist; Karstens et al., 2018)

I know better refers to the incongruency between participants' professional training and clinical reasoning versus the SBT recommendations. Both professions questioned whether the SBT could stratify patients correctly or whether stratification could be adjusted if necessary $(36,47)$. Specifically, physiotherapists found that a patient's category might change during treatment. In addition, some GPs and physiotherapists identified the SBT as redundant as it did not provide additional information $(36,45,49)$.

I'm not using the tool at all... The tool wasn't really showing me something I didn't already know from my interview and exam. (GP; Hsu et al., 2019)

A few GPs confessed they were not using the SBT, not only because LBP was not a priority for them, but that it was a clinically uninteresting condition that often did not require a GP visit $(45,47)$. Others felt conditions such as heart disease and diabetes took precedence over LBP (47). Physiotherapists also noticed when they referred patients back to GPs due to unsuccessful treatment, GPs were reluctant to engage with patients (46).

Yeah, the sort of patients who don't seem to respond to what I do [...] the GPs never want to really see them they just sign them off with sick notes and give them anti-depressants and things like that... (Physiotherapist; Sanders et al., 2014)

Changing me as a health professional, illustrates how the SBT affected the professional attributes of GPs and physiotherapists. Both professions expressed that the SBT improved their confidence when dealing with the psychosocial factors that often accompany chronic LBP (45-47).

And I think now l've got more confidence in how to deal with some of the things they're saying to me. Before if I'd done that and I wasn't confident I think I would've reverted back. (Physiotherapist; Sanders et al., 2014)

Physiotherapists found the SBT training was useful as it helped them reflect on their current practice and gave a fresh perspective on the treatment for LBP. Additionally, they reported a shift in focus from a biomedical approach to a biopsychosocial one $(45,46)$.

It made me reflect on things and it's helped me see, identify some habits that I probably have got into over the years that I need to look at changing. (Physiotherapist; Sanders et al., 2014)

Some physiotherapists experienced increased engagement and motivation in their new role and found that dealing with the psychosocial aspects of LBP was more rewarding and intellectually stimulating $(4,44,46)$.

[...] the social side of it, of people's lives and their problems and things like that and seeing if you can problem solve with that ... I find that more interesting than dishing out a sheet of exercises. (Physiotherapist; Sanders et al., 2014)

Page 9/18 
Conversely, a prominent concern of GPs was that using the SBT would reduce clinical autonomy and would undermine GPs' professional identity (49). Physiotherapists were also fearful that addressing more psychosocial aspects and using fewer traditional hands-on treatments could decrease patient respect $(4,46)$. Karstens and colleagues $(4)$ also reported that some physiotherapists were afraid that selected areas of traditional treatment would become obsolete.

[...] the more you as a physiotherapist address these psycho-social aspects of medicine, don't you risk rationalising yourself out of the picture? (Physiotherapist; Karstens et al., 2018)

Theme 3: It's all about the patient

The theme 'it's all about the patient' emphasised how the SBT may affect patients and their potential reactions to risk stratification and matched treatments. Both professions identified three areas to be considered prior to implementation: patient individuality, the influence of patient demand on decision making, and a patient's motivation to improve.

Participants felt they were pigeonholing patients by stratifying them into one of only three groups which they felt fails to consider patient individuality $(4,47)$.

[...] I'm one of these that thinks that there's an art to general practice and it's more a sort of conversation and a feeling between two people. Now, you can't put feelings into a questionnaire [reference to the tool] so what's right for one, is completely wrong for another and unless you had a questionnaire that was a thousand questions long, you're just not going to capture that, are you? (GP; Sanders et al., 2011)

Both professions agreed that patient demand could significantly influence decision-making surrounding referrals (36, $46,47)$. These participants recognised that patients have rights to request specific treatment and therefore they felt the need to consider the requests to keep generating business.

Whereas, with a patient it's more of, I don't know how to put it really, it's not like a bartering but it is a bit like that you know. They want physio, [...] and you're thinking well you know, should they have it or not and they may only score one but if they really want physio, they going to get physio because we're here to meet the patient expectations and demand... (GP; Sanders et al., 2011)

On the other hand, certain GPs did not want to take away patient choice, fearing that it would impede rapport and the therapeutic relationship.

So my worry about it is that it sort of dupes the patient decision... it's like a trump card, almost. [...] (GP; Saunders et al., 2016)

Participants mentioned that some patients prefer passive treatments and lack motivation to recover $(4,46,47)$.

If he is really motivated and wants to recover quickly, then things will go faster [...], for those people who enjoy being given a sick note and spending a week or two at home ... (Physiotherapist; Karstens et al., 2018)

On the other hand, some physiotherapists anticipated that this method of treatment may be embraced by patients due to previous unsuccessful treatment. Karstens and colleagues (4) reported that patients who received a preliminary education session prior to physiotherapy presented with an improved attitude towards treatment. Additionally, physiotherapists found the SBT encouraged patient engagement in treatment (46).

[...] it means you've got a totally different starting point with the patient, [...] the patient is pro-active, and we can get away from never-ending treatment sessions. (Physiotherapist; Karstens et al., 2018) 
When considering patient-clinician interactions and how patient-centred care was affected, both professions highlighted that the SBT enhanced communication by enabling conversations with patients regarding different aspects of their LBP $(36,45,46)$.

What was really useful to me was the discussions with the [trainer]... That really changed my focus when talking with patients about back pain, really letting them know that no harm will come to them from being active and how to prepare them appropriately for what physical therapy could offer. (GP; Hsu et al., 2019)

\section{Discussion}

Implementation of a tool to help manage a clinical problem is dependent on the willingness of health practitioners to accept new knowledge and utilise new concepts to drive a change in behaviour. The tool needs to make sense and have meaning to intended users to increase the likelihood of positive impact and successful implementation (46). This review captures the perspectives on the use of the SBT and how health practitioners feel it may influence their practice.

\section{Summary of Results}

The main themes identified health practitioner perspectives that influenced the use of the SBT. Participants felt the SBT enhanced their practice though many found it constrained the use of their diagnostic skills. Time constraints were of concern, but many felt that if they put time in to making it habitual practice, using the SBT could become efficient. Involving patients in decision making on their treatment was thought to be one of the benefits of using the SBT, though some GPs felt it had the potential to limit treatment options.

Physiotherapists and GPs felt the psychosocial education during the SBT training added to their skills and ability to treat more complex patients. Many would have valued additional support with this after they'd had a chance to use it in practice.

The wide range of pathologies GPs encounter meant they often placed LBP as a low priority meaning they discharged patients with chronic LBP sooner than physiotherapists believed was optimal. However, using the SBT gave physiotherapists and GPs a better understanding of each other's management of LBP resulting in an improved interprofessional relationship.

Physiotherapists had concerns about the financial implications of using the SBT and the ability to translate it into their specific healthcare system. Many felt that once proficient in the use of the SBT, their skills should be recognised financially.

\section{Findings in relation to existing literature and guidance}

The STarT Back Tool stratifies patients with LBP to receive appropriate matched treatment at an optimal time point (32). Most participants felt that the SBT served its purpose as a stratification tool and enhanced their practice. However, a contrasting view from some physiotherapists and GPs was that - the SBT prevented them from exercising autonomy. Additionally, the inclusion of the SBT in some clinical guidelines gives the impression of compulsion for some participants, preventing the use of the diagnostic skills they have developed through clinical experience. The ability to diagnose often involves pattern recognition, which many GPs view as a component of 'the art of practice' (50). However reliance on pattern recognition can result in a longer pathway to effective treatment and using the SBT has been shown to enhance rather than detract from effective practice (15). The training focuses on the key messages, that the SBT is designed to: aid, not take over clinical decision making; improve the efficiency of LBP management; and help manage high and challenging caseloads $(34,51)$. 
A finding from this review was that some GPs perceived LBP to be a low priority, a finding corroborated by Poitras and colleagues (52) who reported on barriers to the use of LBP management guidelines by health practitioners. Physiotherapists reported that patients with chronic LBP were discharged from their GP prematurely, with GPS expressing that their clinical expertise was better spent on major chronic conditions. GPs reported that guidelines were of low impact and that LBP represented a limited, clinically uninteresting portion of their caseload. This perception may stem from their requirement to manage a wide range of health conditions; in Australia, LBP only accounts for $1.8 \%$ of GPs caseload despite being the eighth most common condition they manage (51). Many GPs also express a lack of confidence and understanding of chronic LBP, with authors reporting that the more complex a patient is, the less willing GPs are to address the problem in its entirety $(53,54)$. The belief that LBP is not a serious condition may explain why some patients are dismissed as malingerers. Frequently such patients have underlying psychosocial factors inhibiting their recovery and if not addressed early, there is an increased risk they will experience fear-avoidance behaviour (55) and may enter a cycle of pain, suffering and disability.

A promising finding from the current review was that physiotherapists and GPs expressed increased engagement in their role following the SBT training, due to increased confidence in addressing psychosocial factors $(52,56,57)$. This facilitated a shift from a biomedical to a biopsychosocial approach (20), adding a new dimension to routine care. Synnott and colleagues (57), reported on physiotherapy perspectives of managing psychosocial dimensions of LBP after intensive training. Participants described increased confidence and an improved level of skill in the management of patients with chronic LBP.

Some participants in this review believed that allowing patients a choice of treatment options made them the centre of decision-making. GPs expressed concern that stratified care could limit options and result in a loss of patient choice and independence. Loss of patient autonomy has been shown to negatively affect patient biopsychosocial wellbeing (5860). However, it is a matter of debate how much clinicians should allow patients to dictate their treatment. Health practitioners often deal with the internal conflict between a paternalistic approach of doing what is best for the patient and cultivating patient autonomy $(58,60)$. An example of this is whether imaging should be undertaken for LBP in the absence of red flags (61). In some cases imaging may reassure the patient that there are no abnormal findings, but early imaging for acute LBP has been correlated with increased sick leave and likelihood of surgery, and an overall poorer prognosis (62). Consequently, when patients express a strong treatment preference, GPs and physiotherapists can choose to grant patient requests, to maintain therapeutic relationships or deny requests with the intention of doing what is best for the patient $(60,63)$.

\section{Strengths and limitations of the study}

Strengths of this study include the use of PRISMA guidelines and the CASP tool. The data analysis was subjected to a rigorous peer-review process; FT and GA presented their initial coding to NS and JH and there was discussion and recoding to ensure that each code reflected the participant data accurately. The process of writing the results yielded several iterations and refinements to the themes which were agreed upon by all authors. Studies were included from four countries, and participants had a range of experience in their professions. There was a dearth of studies undertaken outside the UK, despite undertaking a sensitive search of seven data bases and contacting key authors in the area. This may be due to the relatively recent implementation of the SBT in countries other than the UK. One limitation was that only four studies had participants who had used the SBT $(36,45-47)$, the remainder had been educated and were contemplating it's use $(4,44,48,49)$. Although this pre implementation data is of interest, it is not experiential.

\section{Clinical and research implications}

In the United Kingdom (UK) healthcare is primarily publicly funded by the National Health Service (NHS) (64). The STarT Back Tool was developed in the UK and hence was specifically designed to fit their funding model. Research in other

Page $12 / 18$ 
countries is needed to gain an understanding of how the SBT can be translated and adapted to fit health practitioners working in other health funding models. Consultation and collaboration with health practitionners and other stakeholders is required to facilitate development and effective translation of the SBT into their environment. Understanding how different healthcare systems implement stratified care will help to develop an effective system for managing people with LBP. Furthermore, whilst evidence-based practice has a significant role in the translation and implementation of the SBT, patient expectation and satisfaction are equally important for successful implementation. Further research needs to focus on patient self-reported clinical outcomes using the SBT approach and their satisfaction with the care they received.

\section{Conclusion}

This review highlights perspectives of GPs and physiotherapists in the use of the SBT. Clinicians are open to the possibility of using the SBT and can see some positives for practice despite some misgivings. It may improve interprofessional understanding and help provide more cohesive management of LBP patients. Widespread implementation of the SBT presents significant challenges for some health practitioners in loss of revenue and a perceived loss of autonomy.

The translation of a clinical tool designed for a specific health system to a different context necessitates consideration of many factors and consultation with stake holders. This will facilitate adaptation of the SBT approach for each country's healthcare system.

\section{Abbreviations}

LBP: Low back pain

CASP: Critical Appraisal Skills Programme

\section{Declarations}

Consent for publication - Not applicable

Availability of data and materials - Not applicable

Competing interests - "The authors declare that they have no competing interests"

Funding - Faculty of Health and Environmental Studies, Auckland University of Technology

Ethics approval and consent to participate: Not applicable

Authors' contributions

JH designed the study, assessed identified literature for eligibility, confirmed accurate, consistent data extraction and quality assessment. NS designed the study. FT carried out the literature search, quality assessment and data extraction. GA and FT analysed the findings. All authors contributed to identification of the themes and analysis of the themes and drafted the manuscript.

Acknowledgements - None

\section{Availability of Data and Materials:}


Not applicable. This was a qualitative systematic review of studies investigating perspectives of health practitioners. As such the data used and themes generated were from existing studies and hence the data sets are not supplied.

\section{References}

1. Fernández-de-las-Peñas C, Hernández-Barrera V, Alonso-Blanco C, Palacios-Ceña D, Carrasco-Garrido P, JiménezSánchez S, et al. Prevalence of neck and low back pain in community-dwelling adults in Spain: a population-based national study. Spine (Phila Pa 1976). 2011;36(3):E213-E9.

2. Hartvigsen J, Hancock MJ, Kongsted A, Louw Q, Ferreira ML, Genevay S, et al. What low back pain is and why we need to pay attention. Lancet (London, England). 2018;391(10137):2356-67.

3. Hoy D, Christopher B, Gail W, Lyn M, Peter B, Fiona B, et al. A systematic review of the global prevalence of low back pain. Arthritis Rheum. 2012;64(6):2028-37.

4. Karstens S, Kuithan P, Joos S, Hill JC, Wensing M, Steinhäuser J, et al. Physiotherapists' views of implementing a stratified treatment approach for patients with low back pain in Germany: A qualitative study. BMC Health Serv Res. 2018;18(1):1-12.

5. Meucci RD, Fassa AG, Faria NM. Prevalence of chronic low back pain: Systematic review. Rev Saude Publica. 2015;49(73):1-10.

6. Smith E, Hoy D, Marita C, Theo V, Mohsen N, Rachelle B, et al. The global burden of other musculoskeletal disorders: estimates from the Global Burden of Disease 2010 study. Ann Rheum Dis. 2014;73(8):1462-9.

7. Walker BF. The Prevalence of Low Back Pain: A Systematic Review of the Literature from 1966 to 1998. J Spinal Disord. 2000;13(3):205.

8. Bier JD, Sandee-Geurts J, Ostelo R, Koes BW, Verhagen AP. Can primary care for back and/or neck pain in The Netherlands benefit from stratification for risk groups according to the STarT Back Tool tool classification? Arch Phys Med Rehabil. 2018;99(1):65-71.

9. Dunn KM, Hestbaek L, Cassidy JD. Low back pain across the life course. Best Practice and Research: Clinical Rheumatology. 2013;27(5):591-600.

10. Dunn KM, Jordan K, Croft PR. Characterizing the course of low back pain: A latent class analysis. 2006. p. 754 61.

11. Hestbaek L, Leboeuf-Yde C, Manniche C. Low back pain: what is the long-term course? A review of studies of general patient populations. 2003. p. 149-65.

12. Kolb E, Canjuga M, Bauer GF, Laeubl T. Course of Back Pain Across 5 Years A Retrospective Cohort Study in the General Population of Switzerland. 2011. p. E268-E73.

13. van Oostrom SH, Monique Verschuren WM, de Vet HC, Picavet HS. Ten year course of low back pain in an adult population-based cohort - The Doetinchem Cohort Study. European Journal of Pain. 2011;15(9):993-8.

14. Campbell P, Foster NE, Thomas E, Dunn KM. Prognostic Indicators of Low Back Pain in Primary Care: Five-Year Prospective Study. p. $873-83$.

15. Hill JC, Whitehurst DG, Lewis M, Bryan S, Dunn KM, Foster NE, et al. Comparison of stratified primary care management for low back pain with current best practice (STarT Back): A randomised controlled trial. The Lancet. 2011;378(9802):1560-71.

16. Dagenais S, Caro J, Haldeman S. A systematic review of low back pain cost of illness studies in the United States and internationally. The spine journal: official journal of the North American Spine Society. 2008;8(1):8-20.

17. Alhowimel A, AlOtaibi M, Radford K, Coulson N. Psychosocial factors associated with change in pain and disability outcomes in chronic low back pain patients treated by physiotherapist: A systematic review. SAGE open medicine. 
2018;6:2050312118757387.

18. Brunner E, Probst M, Dankaerts W, Meichtry A, O'Sullivan K. Physical therapists' ability to identify psychological factors and their self-reported competence to manage chronic low back pain. Phys Ther. 2018;98(6):471-9.

19. Ramond-Roquin A, Bouton C, Gobin-Tempereau AS, Huez JF, Airagnes G, Richard I, et al. Interventions focusing on psychosocial risk factors for patients with non-chronic low back pain in primary care-a systematic review. Fam Pract. 2014;31(4).

20. Foster NE, Delitto A. Embedding psychosocial perspectives within clinical management of low back pain: Integration of psychosocially informed management principles into physical therapist practice - challenges and opportunities. Phys Ther. 2011;91(5):790-803.

21. Axén I, Leboeuf-Yde C. Trajectories of low back pain. Best Practice \& Research Clinical Rheumatology. 2013;27(5):601-12.

22. O'Sullivan P, Caneiro JP, O'Keeffe M, O'Sullivan K. Unraveling the Complexity of Low Back Pain. J Orthop Sports Phys Ther. 2016;46(11):932-7.

23. Cherkin D, Balderson B, Wellman R, Hsu C, Sherman KJ, Evers SC, et al. Effect of Low Back Pain Risk-Stratification Strategy on Patient Outcomes and Care Processes: the MATCH Randomized Trial in Primary Care. J Gen Intern Med. 2018;33(8):1324-36.

24. Darlow B, Dean S, Perry M, Mathieson F, Baxter GD, Dowell A. Acute low back pain management in general practice: uncertainty and conflicting certainties. Fam Pract. 2014;31(6):723-32.

25. Foster NE, Thomas E, Bishop A, Dunn KM, Main CJ. Distinctiveness of psychological obstacles to recovery in low back pain patients in primary care. Pain. 2010;148(3):398-406.

26. Sowden G, Hill JC, Konstantinou K, Khanna M, Main CJ, Somerville S, et al. Targeted treatment in primary care for low back pain: The treatment system and clinical training programmes used in the impact back study (ISRCTN 55174281). Fam Pract. 2012;29(1):50-62.

27. Hill J, Bedford J, Houston D, Reid DM, Baxter DG, Ellis R. Exploring Physiotherapists' Use of Clinical Practice Guidelines, Screening, and Stratification Tools for People with Low Back Pain in New Zealand. New Zealand Journal of Physiotherapy. 2020;48(2):59-69.

28. University of Keele. STarT Back: Evidence Based Implementation of Stratified Care [Internet]. Staffordshire, United Kingdom: University of Keele; n.d. [cited 2020 Jul 18]. Available from: https://startback.hfac.keele.ac.uk/.

29. Karran EL, McAuley JH, Traeger AC, Hillier SL, Grabherr L, Russek LN, et al. Can screening instruments accurately determine poor outcome risk in adults with recent onset low back pain? A systematic review and meta-analysis. BMC Med. 2017;15(1):13.

30. Amundsen PA, Evans DW, Rajendran D, Bright P, Bjorkli T, Eldridge S, et al. Inclusion and exclusion criteria used in non-specific low back pain trials: a review of randomised controlled trials published between 2006 and 2012. BMC Musculoskelet Disord. 2018;19(1):113.

31. Hill JC, Dunn KM, Lewis M, Mullis R, Main CJ, Foster NE, et al. A primary care back pain screening tool: Identifying patient subgroups for initial treatment. Arthritis Care Res (Hoboken). 2008;59(5):632-41.

32. Sowden G, Hill JC, Morso L, Louw Q, Foster NE. Advancing practice for back pain through stratified care (STarT Back). Brazilian Journal of Physical Therapy. 2018;22(4):255-64.

33. Foster NE, Mullis R, Hill JC, Lewis M, Whitehurst DGT, Doyle C, et al. Effect of stratified care for low back pain in family practice (IMPaCT Back): A prospective population-based sequential comparison. Ann Fam Med. 2014;12(2):102-11.

34. Foster NE, Hill JC, O'Sullivan P, Hancock M. Stratified models of care. Best Practice \& Research in Clinical Rheumatology. 2013;27(5):649-61.

Page 15/18 
35. Hingorani AD, Windt DAvd, Riley RD, Abrams K, Moons KGM, Steyerberg EW, et al. Prognosis research strategy (PROGRESS) 4: stratified medicine research. BMJ: British Medical Journal (Clinical Research Edition). 2013;346:e5793-e.

36. Bamford A, Nation A, Durrell S, Andronis L, Rule E, McLeod H. Implementing the Keele stratified care model for patients with low back pain: An observational impact study. BMC Musculoskelet Disord. 2017;18(1):1-15.

37. Dziedzic KS, French S, Davis AM, Geelhoed E, Porcheret M. Implementation of musculoskeletal models of care in primary care settings: Theory, practice, evaluation and outcomes for musculoskeletal health in high-income economies. Best Practice \& Research Clinical Rheumatology. 2016;30(3):375-97.

38. Moher D, Liberati A, Tetzlaff J, Altman DG, The Prisma Group. Preferred reporting items for systematic reviews and meta-analyses: The PRISMA statement. PLoS Med. 2009;6(7):e1000097.

39. Critical Appraisal Skills Programme. CASP Qualitative Checklist 2018 [Available from: https://casp-uk.net/wpcontent/uploads/2018/03/CASP-Qualitative-Checklist-2018_fillable_form.pdf.

40. Hannes K. Chapter 4: Critical appraisal of qualitative research. In: Noyes J, Booth A, Hannes K, Harden A, Harris J, Lewin S, et al., editors. Supplementary Guidance for Inclusion of Qualitative Research in Cochrane Systematic Reviews of Interventions: Cochrane Collaboration Qualitative Methods Group; 2011.

41. Braun V, Clarke V. Using thematic analysis in psychology. Qualitative Research in Psychology. 2006;3(2):77-101.

42. Terry G, Hayfield N, Clarke V, Braun V. Thematic Analysis. 2017 2020/04/04. In: The SAGE Handbook of qualitative research in psychology [Internet]. London: SAGE Publications Ltd; [17-36]. Available from:

https://methods.sagepub.com/book/the-sage-handbook-of-qualitative-research-in-psychology-second-edition.

43. Kuithan P, Krug K, Hill JC, Szecsenyi J, Steinhaeuser J, Joos S, et al. German physiotherapists' views on a single appointment for low-risk patients within the start-back approach. Man Ther. 2016;25:e150.

44. Caeiro C, Paiva S, Gomes L, Fernandes R, Canhao H, Rodrigues AM, et al. Barriers and facilitators to the implementation of a stratified model of care for low back pain patients in primary care in Portugal. Ann Rheum Dis. 2019;78:2060-1.

45. Hsu C, Evers S, Balderson BH, Sherman KJ, Foster NE, Estlin K, et al. Adaptation and implementation of the STarT Back risk stratification strategy in a US health care organization: A process evaluation. Pain Med. 2019;20(6):110519.

46. Sanders T, Ong BN, Sowden G, Foster N. Implementing change in physiotherapy: Professions, contexts and interventions. Journal of Health Organization and Management. 2014;28(1):96-114.

47. Sanders T, Foster NE, Ong BN. Perceptions of general practitioners towards the use of a new system for treating back pain: A qualitative interview study. BMC Med. 2011;9(49):1-11.

48. Karstens S, Joos S, Hill JC, Krug K, Szecsenyi J, Steinhäuser J. General practitioners views of implementing a stratified treatment approach for low back pain in Germany: A qualitative study. PLoS One. 2015;10(8):1-14.

49. Saunders B, Bartlam B, Foster NE, Hill JC, Cooper V, Protheroe J. General Practitioners' and patients' perceptions towards stratified care: A theory informed investigation. BMC Fam Pract. 2016;17(125):1-15.

50. Schwartz A, Elstein A. Clinical reasoning in medicine. In: Higgs J, Jones M, Loftus S, Christensen N, editors. Clinical reasoning in the health professions e-book. 3 ed: Elsevier Health Sciences; 2008.

51. Koes BW, van Tulder M, Lin CC, Macedo LG, McAuley J, Maher C. An updated overview of clinical guidelines for the management of non-specific low back pain in primary care. Eur Spine J. 2010;19(12):2075-94.

52. Poitras S, Durand M, Côté A, Tousignant M. Guidelines on low back pain disability: Interprofessional comparison of use between general practitioners, occupational therapists, and physiotherapists. Spine (Phila Pa 1976).

2012;37(14):1252-9.

Page 16/18 
53. Gardner T, Refshauge K, Smith L, McAuley J, Hübscher M, Goodall S. Physiotherapists' beliefs and attitudes influence clinical practice in chronic low back pain: A systematic review of quantitative and qualitative studies. $J$ Physiother. 2017;63(3):132-43.

54. Parsons S, Harding G, Breen A, Foster N, Pincus T, Vogel S, et al. The influence of patients' and primary care practitioners' beliefs and expectations about chronic musculoskeletal pain on the process of care: A systematic review of qualitative studies. Clin J Pain. 2007;23:91-8.

55. George SZ, Beneciuk JM. Psychological predictors of recovery from low back pain: A prospective study. BMC Musculoskelet Disord. 2015;16:1-7.

56. Franca AA, dos Santos V, Filho RL, Pires KF, Lagoa KF, Martins WR. 'It's very complicated': Perspectives and beliefs of newly graduated physiotherapists about the biopsychosocial model for treating people experiencing non-specific low back pain in Brazil. Musculoskeletal Science and Practice. 2019;42:84-9.

57. Synnott A, O’Keeffe M, Bunzli S, Dankaerts W, O'Sullivan P, Robinson K, et al. Physiotherapists report improved understanding of and attitude toward the cognitive, psychological and social dimensions of chronic low back pain after cognitive functional therapy training: A qualitative study. J Physiother. 2016;62(4):215-21.

58. Rodriguez-Osorio CA, Dominguez-Cherit G. Medical decision making: Paternalism versus patient-centered (autonomous) care. Curr Opin Crit Care. 2008;14(6):708-13.

59. Lupton D. Doctors on the medical profession. Sociol Health IIIn. 1997;19(4):480-97.

60. Zolkefli Y. Evaluating the concept of choice in healthcare. The Malaysian Journal of Medical Sciences. 2017;24(6):92-6.

61. Steffens D, Hancock MJ, Maher CG, Williams C, Jensen TS, Latimer J. Does magnetic resonance imaging predict future low back pain? A systematic review. European Journal of Pain. 2014;18(6):755-65.

62. Brukner P, Khan K. Brukner \& Khan's clinical sports medicine: Injuries 5th ed. Australia: McGraw-Hill Education; 2017.

63. Breen A, Austin H, Campion-Smith C, Carr E, Mann E. "You feel so hopeless": A qualitative study of GP management of acute back pain. European Journal of Pain. 2007;11(1):21-9.

64. Main CJ, Sowden G, Hill JC, Watson PJ, Hay EM. Integrating physical and psychological approaches to treatment in low back pain: the development and content of the STarT Back trial's 'high-risk' intervention (StarT Back; ISRCTN 37113406). Physiotherapy. 2012;98(2):110-7.

\section{Figures}




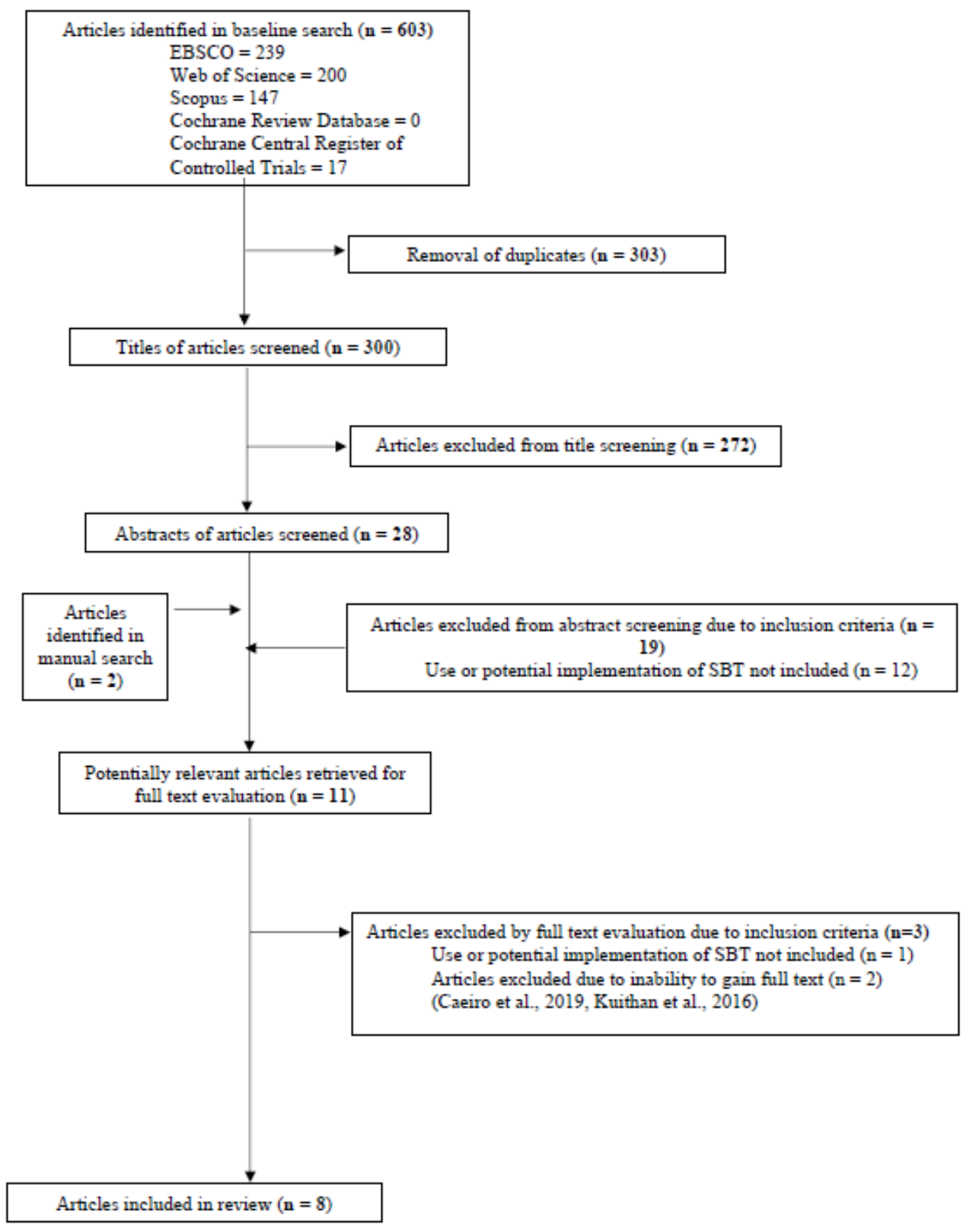

\section{Figure 1}

Study selection process 